\title{
Literature Review on Influence Factors of the Growth of Reed
}

\author{
C.L. Chu, X.X. Ruan, G.Z. Wang, K. Wu, Y.R. Li, J. Li \& D.D. Wang \\ College of Environmental science and engineering, NanKai University, China
}

\begin{abstract}
KEYWORD: Reed; Influence factors; Soil physical and chemical properties; Water quality factors; Heavy metal content

ABSTRACT: Reed is common plant in wetland and its ecological function in wetland and strong pollutant degradation ability has been paid more and more attention. So far, reed cultivation has become an important part of ecological restoration in wetland. Substantial studies have been made concerning influence factors of the growth of reed both at home and abroad. Based on existing research, this paper analyzes the main influence factors of the growth of reed, including soil physical and chemical properties, water quality factors, heavy metal content and etc, and puts forward the studies content that should be strengthened in the future.
\end{abstract}

\section{BACKGROUND}

As a common plant in the wetland, reed grows well by the side of river swampy ground, irrigation ditches and so on. Reed plays an important role in breaking the force of wind, preserving the temperature, adjusting the mositure, purifying the air, improving the environment, maintaining the ecological balce, adjusting the climate and so on. It also has great instruction significance in constructing man-made wetland.

Reed is the raw material of paper making, and construction industry, so it has huge economic value. what's more, it also has huge ecological value for it can preserve the water resources, and adjust the climate. With the help of the onsite experiment study, literature review, and expert consultation The researchers study and determine the general characteristic index of reed growth as population density, leaf area, number of plant leaves, plant height, branch diameter and so on. The main factors and mechanisms that influence the reed growth are put forward, which provides theoretical and scientific support for wetland restoration engineer.

\section{SOIL PHYSICAL AND CHEMICAL PROPERTIES}

\section{volume weight of soil}

Volume weight of soil refers to the ratio between the weight of given dried soil (including soil particle and the small openings between particles) and the water weight of the same volume. It relates to the soil texture, compaction condition, soil bulk density, soil organic matter content, and all kinds of soil management methods. Volume weight of soil reflects the soil porosity and compactness. It has huge impact on the soil permeability, infiltration property, moisture holding capacity, solute transport characteristics, and soil anti erosion ability ${ }^{[1]}$.

soil porosity has negative correlation with volume weight, while compactness has positive correlation with volume weight ${ }^{[2]}$. High volume weight soil has high compactness, thus it is difficult for the seed to sprout and for the young plant to come out of the earth, which will delay the seedling emergence, affect the rate of emergence, emergence uniformity and so on. While the low porosity will cause the poor ventilation, weak mocrobial activity, slow organic matter decomposition, and low available nutrient content, which is not good for plant growth.

If the soil is too loose, its volume weight will be low, thus the plant roots can not get in touch closely with the soil particles, which will make it difficult for the roots to absorb the water and fertilizer, and even lead to hanging phenomenon and lodging phenomenon. While High porosity will lead to water and fertilizer leakage, poor temperature preservation will affect the plant growth. Lian Jianhua chose three kinds of plant seeds to conduct experiments which showed that with the increase of soil weight volume, the emergence rate and potential decreased for all the three plants, the 
root length decreased, and the number of organism underground and on the ground decreased too ${ }^{[3]}$. While Zhang Aiqin and her team proved that the reed height was greatly influenced by soil weight volume $^{[4]}$.

The present studies mostly focus on the spatial variability of soil weight volume vertically or horizontally $^{[5-6]}$ and relative impact of soil weight volume on soil water conservation capacity, permeability, and mineral reserves. In this way, land health status or quality can be reflected or evaluated ${ }^{[7-}$ ${ }^{9]}$. The ring shear testing is widely adopted and standardized for its universality and convenience.

\section{soil moisture content and salinity}

Soil moisture content refers to the mositure contained in the water. Generally, it refers to the water weight in the $100 \mathrm{~g}$ oven-dried soil. Soil salinity is usually expressed by $\mathrm{Ms} / \mathrm{cm}$. The nature and content of salts in the soil have different influence on different plants and different growth periods of plant or different growth situations. Complex relationship also exists between different soil salts or soil moisture content and soil salinity.

Early experiments showed that the more the moisture content, the lower the salt in the soil, the better the plants grow ${ }^{[10]}$. Mao Xiuhong et. all specifically demonstrated the plant salt damage mechanism ${ }^{[11]}$. With the help of Pearson's correlation analysis method to study the relationship among soil water, conductivity, reed growth and species distribution, Yang Fan et. all indicated the significant correlation between soil moisture content and conductivity and reed growth index (coverage, average plant height, biomass dry weight and fresh weight), which was a significant influence factor for the reed growth ${ }^{[12]}$.

H.L.B.K., Gulinaer studied the relationship between photosynthetic rate and soil moisture and salt content and reached the same conclusion. The present literature is mainly about the influence of soil moisture and salt content on the properties and productivity of given plant, thus land health status or quality could be evaluated on the basis of the study ${ }^{[14-17]}$. Or, a more more accurate remote sensing monitoring is adopted to monitor the real time variation of soil moisture content. For example, the new mode of sensor ERRA-MODIS uses advanced synthetic aperture radar ASAR image monitoring and ground penetrating radar monitoring, produces and analyzes a more detailed empirical model, and realizes the remote sensing inversion of soil moisture content ${ }^{[18-20]}$, and the adaptability and salt tolerance of given plant to given kind of soil, especially the adaptability of salt tolerant plants to saline soil.

\section{soil organic matter, total nitrogen content and total phosphorus content}

Soil organic matter, total nitrogen content and total phosphorus content is important indexes to measure the soil fertility. Song Chunyu et all studied the influence of soil organic matter and its components on soil fertility and plant productivity. The study showed that soil organic matter, total nitrogen content and total phosphorus content had a positive correlation with plant productivity; what's more, a threshold value was determined for the highest productivity ${ }^{[21]}$. Study from Li Zhiwei showed that too much nitrogen would restrain the plant growth, while too much phosphorus would cause over absorption ${ }^{[22]}$. Wetland experiment conducted by Li Hui et all in Huixian, Guilin Province proved that the higher content of nitrogen, phosphorus and organic matters, the better reed would grow ${ }^{[23]}$. Zheng Yunyun compared the nutrient contents in the reed degraded area and non degenerate region, and proved that no exogenous fertility input was one major reason for the reed degeneration in Liaohe Estuary ${ }^{[24]}$. On the other hand, the most recent studies mainly focus on the spatial distribution characteristics and its variability of organic matter and nutrient elements, which will lead to the drawings of carbon nitrogen ration and temporal and spatial distribution of nitrogen and phosphorus in the region ${ }^{[25]}$. Or, the studies focus on the impact of using nitrogen phosphorus fertilizer and the fertilization intensity on the plant growth and shapes ${ }^{[26-28]}$. Only a minority of researches focus on the existing forms of organic matter and nutrient elements in the soil and its thermostability and other characteristics. 


\section{WATER QUALITY FACTOR}

As emergent aquatic plant, reed possesses the physiological property to live in the water environment for its adventitious roots, root stock, and stalk. Water quality factors play a comprehensive role in adjusting, transporting all kinds of elements during the reed growth. The management of water quality factor will directly influence the quality and production of reed. Studies concerning the impact of water quality factors on emergent aquatic plant mainly focus on water depth, COD, TP, TN and other simple factors. Studies have proven that as the water deepens, reed grows higher, the number of biomass increases, while the growth rate of reed decrease ${ }^{[29-30]}$. Zhang Aile etc. all discovered that the higher DO, the lower COD, the better plants grow ${ }^{[31]}$. Ren Jun studied the growth traits of the same reed in different pollutant water environment and thought that the increase concentration of COD and TP will hinder the growth of ground diameter of reed; while the increase concentration of TN will promote the leaf width, stem height and the leaf length ${ }^{[32]}$.

\section{HEAVY METAL ELEMENT}

Number Heavy metal elements refer to those whose density surpasses $4.5 \mathrm{~g} / \mathrm{cm}^{3}$. Related studies are mainly about the impact of several heavy metal elements on the plant growth. These heavy metals are Cadmium, lead, mercury, chromium, copper and zinc and metalloid arsenic, whose biotoxicity was much obvious. Based on the previous studies, the biotoxicity mechanism of heavy metal elements can be generalized: too much cadmium will destroy the chlorophyll structure in the leaves; too much lead will decrease the mitotic rate of the root; too much mercury will interfere the protein synthesis and cause the Molecular conformation change; too much arsenic interferes the metabolization of phosphorus and Reduced glutathione; Oxidative stress of cadmium, lead, mercury and arsenic leads to the fast increase of active free radicals and the destruction to the metabolic enzyme system. chromium of high concentration, especially six valence chromium causes serious toxic action, but the mechanism is not very clear. Too much copper interferes the absorption and circulation of ferrous and restrain the decarboxylase activity. Too much $\mathrm{Zn}$ harms the root system. Nuerguli Amuti, Jiang Xingyu, Wang Zhengqiu et all studied specifically the toxic mechanism of cadmium, lead and zinc on reed growth ${ }^{[33-35]}$. Studies about the influence of other heavy metals on reed are comparatively less. While the most recent studies mainly focus on the spatial distribution of heavy metal factors and solution to getting rid of the heavy metal pollution ${ }^{[36-37]}$, or on finding and cultivating heavy metal resistant bacteria colony or heavy metal enrichment plants to restrain and cope with heavy metal pollution ${ }^{[38-39]}$.

\section{ACKNOWLEDGEMENT}

This study was supported by the project of National Natural Science Foundation of China (No. 41301624) and the Research funds of Tianjin education social science major projects (mechanism and ways of ecological reform of industry of Tianjin by green consumption).

\section{REFERENCE}

[1] J.Y., Zheng., M.A., Shao., \&X.C., Zhang.(2004).Spatial Variation of Surface Soil 's Bulk Density and Saturated Hydraulic Conductivity on Slope in Loess Region. Journal of Soil and Water Conservation, 18(3): 53-56.

[2] Z. H., Li., S.,H., Wang.(2000). Effects of soil bulk density on soil physical properties and wheat growth. CHINESE JOURNAL OF SOIL SCIENCE, Vol.31, No.2.

[3] J.H., Liang., Q.P., Li., R.H., Han., \&P., Chen.(2009). Effect of Different Soil Bulk Density on the Germination and Growth of Three Plants. Guangdong Landscape Architecture, (2009)04: 2225.

[4] A.Q, Zhang., H.Y., Qi, \& J.N., Wang.(2006). Grey correlative degree analysis between growth of bulrush and soil factors of wetlands. TERRITORY \& NATURAL RESOURCES STUDY, 
2006(3): 65-66.

[5] B., Yu., X.H.,Wu.(2016). Slope-Aspect Driven Variation of Soil Physicochemical Properties and Saturated Hydraulic Conductivity in Dongshan Experimental Forest Farm of Taiyuan City. Research of Soil and Water Conservation, Vol.23, No.1.

[6] C.,Zhang., S.H., Chen., et al.(2014). Spatial variation characteristics of surface soil water content, bulk density and saturated hydraulic conductivity on Karst slopes. Chinese Journal of Applied Ecology. 2014,25(6):1585-1591

[7] Z., Li., P.T., Wu., et al.(2010). Simulated experiment on effects of soil bulk density on water holding capacity. ACTA PEDOLOGICA SINICA, 2010,47(4):611-620

[8] H., Chai., N.P., He.(2016). Evaluation of soil bulk density in Chinese terrestrial ecosystems for determination of soil carbon storage on a regional scale. ACTA PEDOLOGICA SINICA, 2016,36(13)

[9] W.J., Zhao., W., Yu, et al.(2016). Influences of Soil Bulk Density on Point Source Infiltration Pattern Under Drip Irrigation Condition in Gravel-sand Mulch Soil. Bulletin of Soil and Water Conservation. 2016(01).

[10] J., Ding.(1960). The effect of soil moisture content and salt concentration on the growth of plants. Acta Biologiae ExperÌmentalis Sillìca, 1960(Z1).

[11] X.H., Mao., C.L., Liu., L.P., Yan., et al.(2010). Plant salt injury mechanism and the strategy of response to salt stress. SHANDONG FORESTRY SCIENCE AND TECHNOLOGY, 2010, 40(4): 128-130.

[12] F., Yang., W., Deng., J.F., Yang., et al.(2006). Effects of Soil Moisture and Electrical Conductivity on Growth and Population Distribution of Phragmites australis. Journal of Soil and Water Conservation, 2006, 20(04): 199-201.

[13] H.L.B.K., Gulinaer.(2012). The Soil Salinity Effects on The Growth of Phragmites Australis in Yu Tian Oasis. Xinjiang University, 2012.

[14] D., Kong.(2004). Study on Crop Response to Soil Water-Salt and its Modelling for Saline Soil under Water-saving Irrigation. Inner Mongolia Agricultural University,2004.

[15] G.F., Yuan., P., Zhang., et al.(2012). Change characteristics in soil water content in root zone and evidence of root hydraulic lift in Tamarix ramosissima thickets on sand dunes. Chinese Journal of Plant Ecology, 2012,36(10):1033-1042

[16] J.Y., Jiao., K., Chen., \&C.Y., Yin.(2010). Effects of soil moisture content on growth, physiological and biochemical characteristics of Jatropha curcas L. Acta Ecologica Sinica, 2010, 30(16):4460-4466

[17] J.X., Wang., Q.J., Wang., et al.(2010). Effects of mineralization of irrigation water and soil salinity on cotton emergence rate in Southern Xinjiang Uygur Autonomous Region of China. Transactions of the CSAE, 2010, 26(9): 28-3.

[18] L.J., Zhao.(2004). Research on the Remote Sensing Information Models of Soil Moisture Based on MODIS Data in Beijing. China Agricultural University, 2004.

[19] Y.S., Bao., L.Y., Liu., et al.(2006). Estimation of Soil Water Content and Wheat Coverage with ASAR Image. JOURNAL OF REMOTE SENSING, 2006, 10(2):263-271.

[20] Q.F., Wang., K.F., Zhou., et al.(2006). A Study of Fast Estimating Soil Water Content by Ground Penetrating Radar. JOURNAL OF NATURAL RESOURCES, 2013, 28(5):881-888. [21] C.Y., Song., Y.Y., Zhang., et al.(2008). Effect of Soil Organic Matter on Soil Fertility and Crop Productivity. SYSTEM SCIENCES AND COMPREHENSIVE STUDIES IN AGRICULTURE, 2008, 24(03): 357-362.

[22] Z.W., Li.(2010). Effects of Excessive Nitrogen and Phosphate Fertilizer on the Growth of the Plant and the Regulating Action of the Manure. Agricultural University of Hebei, 2010 [23] H., Li., P.F., Huang., et al.(2008). Response of Reed and Soil Organic Matter, Soil Total Nitrogen, Soil Total Phosphorus in Huixian Wetland. Journal of Anhui Agri. Sci. 2012,40( 6) : 32953297. 
[24] Y.Y., Zheng. Soil physicochemical properties and its effect on the growth of Phragmites australis in Liaohe degraded wetland. Ocean university of China, 2014.

[25] Q.J., Zhang., X.B., Yu., J.X., Qian., T., Xiong.(2012). Distribution characteristics of plant communities and soil organic matter and main nutrients in the Poyang Lake Nanji Wetland. Acta Ecologica Sinica, 2012,32( 12) : 3656-3669.

[26] X.L., Yang., Y.L., Lu., et al.(2013). Effects of long-term N application and straw returning on $\mathrm{N}$ budget under wheat-maize rotation system. Plant Nutrition and Fertilizer Science, 2013,19( 1) : $65-73$.

[27] Y.X., Chen., X.H., Chen., et al.(2014). Effect of nitrogen fertilizer on dry matter accumulation and yield in wheat /maize /soybean intercropping systems. ACTA P R ATACULTU R AE SINICA, 2014, 23(1):73-83.

[28] L., Chen., S.F., Wang., R.L., Liu., H., Wang.(2012). Changes of root morphology and rhizosphere processes of wheat under different phosphate supply. Plant Nutrition and Fertilizer Science, 2012(2):324-331.

[29] Y., Li.(2012). The influence of water on reed growth. modern agriculture, 2012(8): 66-67.

[30] Y.W., Li., F., Mao.(2011). The influence on biomass of reed caused by water in Zhalong Wetland. Inner Mongolia Science Technology \& Economy, 2011(9): 67-68.

[31] A.Q., Zhang., M.L., Gao., \& H., Zhao.(2005). Research on Relationship of Reed Growth and Water in Zhalong Wetland. Heilongjiang Environmental Journal, 2005, 29(04): 29-30.

[32] J., Ren., L., Tao., et al.(2011). Effect of Sewage Environment on Reed Growth Characteristics. Environmental Science \& Technology, 2011, 33(10).

[33] H.Y., Lu., et al.(2013). Study on changes of chlorophyll content in Reed Leaves Under Heavy Metal Pollution. Northern Horticulture, 2013(21): 57-60.

[34] X.Y., Jiang.(2001). Heavy metal damages of Reed and its resistance mechanism. Shandong Agricultural University,2001.

[35]Z.Q.,Wang.,X.Y.,Jiang.,C.H.,Wang. Effects of Pb, Cd, and Zn on Oxidative Stress and Antioxidative Ability in phragmites australis. Chinese Journal of Process Engineering, 2002, 2(6):558-563. [36] L.M., Lei., D.S., Yu., et al.(2014). Spatial distribution and sources of heavy metals in soils of Jinghui Irrigated Area of Shaanxi, China. Transactions of the Chinese Society of Agricultural Engineering (Transactions of the CSAE), 2014, 30(6): 88-96.

[37] X.M., Zhang., X.Y., Zhang., et al.(2014). Spatial Distribution and Accumulation of Heavy Metal in Arable Land Soil of China. ENVI R ONMENTAL SCIENCE, 2014(2)

[38] Q.Y., Luo., X.J., Wang., et al.(2013). Mechanism and application of bioremediation to heavy metal polluted soil using arbuscular mycorrhizal fungi. Acta Ecologica Sinica, 2013,33( 13) : 38983906.

[39] Y.W., Zhang., L.W., Chai., et al.(2014). Effect of Ectomycorrhizae on Heavy Metals Sequestration by Thermostable Protein in Rhizosphere of Pinus tabulaeformis Under $\mathrm{Cu}$ and $\mathrm{Cd}$ Stress. ENVI R ONMENTAL SCIENCE, 2014, 35(3):1169-1175. 